found to be due to a submarine earthquake which broke up many miles of the ocean floor. The occurrence may be compared with a similar commotion which destroyed an important fishery in the sub-tropical waters of the United States.

A full and comprehensive appreciation of sub-tropical ichthyology is necessary to indicate the vast and interesting variety of the fauna and the intrinsic charm of scientific research. It is the duty and interest of the community to discover the potential genius and place him where he can accomplish that for which he is fitted, unfettered by the suppressing restrictions of a false communistic socialism or cramping of individual effort.

Magna opera Domini exquisitae omnes voluntates ejus.

\title{
Ten Years of X-ray Crystal Analysis.
}

\author{
By Dr. A. E. H: TutTon, F.R.S.
}

A SPECIAL number of Die Naturwissenschaften, entitled "Zehn Jahre Laue-Diagramm," was issued on April 21, forming Heft I6, 1922, which contains eight articles by authors who have contributed to the subject of X-ray analysis on the continent since its first inception by Dr. M. von Laue, among whom may be mentioned Drs. Friedrich and Knipping, who collaborated with Dr. von Laue in the first discovery, Prof. Debye, and Prof. Niggli. Probably the article of deepest interest to the general reader will prove to be that of Dr. Friedrich, who gives an account of the circumstances in the year rgra in Munich when the first discovery was made. To the present writer, who was himself in Munich in the summer of that same remarkable year, this memoir is of fascinating interest. It has to be remembered that the scientific coterie at that time forming the professorial staff of the University, Museum, and Institute, included Prof. Röntgen, the generally recognised discoverer of X-rays (although their production had for some time previously been almost a daily occurrence in the private laboratory of the late Sir William Crookes); Prof. von Groth, the founder and editor of the Zeitschrift für Krystallographie and the doyen of crystallographers, whose brilliant lectures on crystal structure and optics attracted students from all over the world; Prof. Sommerfeld, who had carried on the tradition of X-ray physics bequeathed to him by his predecessor Boltzmann, and also extended the work of Haga and Wind, and of Walther and Pohl on X-radiograms and the general physics of X-rays; Prof. Ewald, who had studied the behaviour of long electromagnetic waves with space-lattices; and Dr. von Laue, who had specialised largely on the interference phenomena of ordinary optics. It was among this strong combination of crystallographers, X-ray specialists, and diffraction (grating) opticians that the inception of the attack on crystals by X-rays had its birth.

During a conversation between Laue and Ewald, the former raised the question as to how electromagnetic waves would behave which were small compared with the grating constants, and from his optical experience. he suggested that diffraction spectra should be produced. The order of the space-lattice cell dimensions of crystals was already known to be about an Ångström unit (10 ${ }^{-8} \mathrm{~cm}$.), from the density and nolecular weight of the crystal and the mass of a hydrogen atom. The work of Sommerfeld and of Walther and Pohl had led us to expect that the order of dimensions of the wavelength of X-rays would be about one-tenth of this (10 ${ }^{-9} \mathrm{~cm}$.). Consequently Laue suggested that the conditions should be particularly favourable for the origination of interference phenomena on the passage of X-rays through crystals.

The discussion was continued in the common room, and taken up by the whole, deeply interested coterie; and Friedrich, who was at the time acting as Sommerfeld's assistant, declared himself, with youthful enthusiasm, ready to test the idea practically. He secured the assistance of Knipping, who had more spare time at his disposal, and together they set up the now famous arrangement of X-ray bulb, leaden screens with slits for ensuring the exit of a definite beam of X-rays, simple goniometer carrying the crystal, and photographic plates to receive the expected radiations. At the first attempt the sensitive plates were only arranged parallel to the primary beam of X-rays, as any effect expected appeared likely to be of the character of secondary rays from the crystal, and it was only on repeating the exposure with a photographic plate arranged behind the crystal, perpendicular to the direct beam, that the first Laue radiogram with a crystal of zinc blende was obtained, after several hours of exposure.

Friedrich describes how excited and delighted he was when, alone in his working room at the Institute late that night, he saw the spots appear on the plate under the influence of the developer, due to the deflected X-rays, now known to be reflected from the planes of atoms within the crystal, the planes of the atomic space-lattice. Next morning he went early to show the negative to Knipping, and together they hastened to Laue and Sommerfeld, who were both naturally equally interested and delighted. Prof. Sommerfeld at once excused his assistant from his ordinary duties, so that he might go ahead with further experiments. Both Profs. von Groth and Röntgen, to whom the result of the experiment was at once communicated, supplied materials and gave valuable advice. A much better and more accurate apparatus was erected, including a good goniometer for the exact adjustment of the crystal (which is particularly necessary), and the excellent X-radiograms of zinc blende, quartz, rock-salt, and other crystallised substances, now so well known were obtained as the immediate results.

Dr. Knipping directs special attention in his article to the remarkable work of Siegbahn, who worked with an evacuated apparatus, so as to exclude air absorption of the X-rays, and measured, the wave-lengths of the "softer" long wave-length portion of the radiation, eventually discovering and measuring rays as long as ten Ångström units. Compton, it will be remembered, at the other extreme, has measured X-rays ( $\gamma$-rays

NO. 2749 , VOL. I IO] 
from radium) on the short wave-length side as short as 0.02 Angström units. Hence, the X-ray spectrum now known comprises waves of all this great range of wave-lengths. It will also be remembered that other researches, such as those of Lyman and Kurth, Mohler and Foote, and Richardson and Bazzoni, have introduced us to rays, termed the $\mathrm{K}, \mathrm{I}, \mathrm{M}$, and $\mathrm{N}$ series, derived by radiations from carbon, oxygen, iron, copper, potassium, sodium, magnesium, and molybdenum, which have wave-lengths ranging to 375 Ångström units, thus bridging over the gap between the shortest ultra-violet rays and X-rays.

Prof. Niggli's contribution offers a survey of the substances the crystal structure of which has now been ascertained by the various $\mathrm{X}$-ray methods of Laue, the Braggs, Debye and Scherrer, and Hull, including a table of the absolute dimensions of the space-lattice cells resulting from the Bragg spectrometric measurements. His concluding remarks are well worth quoting (so far as is possible in a translation from the German), especially when it is remembered that Prof. Niggli has now taken over from Prof. von Groth the editorship of the Zeitschrift für Krystallographie. "By Laue's discovery crystallography not only obtains a new method of investigation, but experiences a new 'liveliness' in almost every one of its branches. Most especially are we mineralogists glad that our colleagues of the sister sciences now bring to the crystal an entirely new attitude of mind and interest than formerly, for only by the combined and simultaneous labours of all can further research move along right lines."

With these words of Prof. Niggli we must all agree, and it would appear that the sentiment is now so universally accepted and recognised that the future is bright with hope for a progress during the next decade as glorious as that which is now recorded at the termination of ten years of X-ray crystal analysis.

\section{O bitu ary.}

Prof. J. C. Kapteyn, For. Mem., R.S.

ACOBUS CORNELIUS KAPTEYN was born at Barneveld, Holland, on January $19, \mathbf{1} 85 \mathrm{x}$. He studied at Utrecht from I869 to I875, and was then appointed an observer at Leiden Observatory, where he remained for two years. In 1878 he was appointed professor of astronomy and theoretical mechanics at the University of Groningen. He was in the unusual position of an astronomical professor without an observatory, and he immediately applied to the Dutch Government for the means to equip a students' observatory; he mentioned in particular a 6-inch heliometer as desirable. The application, however, was unsuccessful, and for a few years his lectures monopolised his attention. Then, finding that he had time to spare and no instruments, he began to look about for some useful astronomical work of a computational kind that he could carry out. Circumstances soon brought a task well fitted to his tastes.

Photography had been revolutionised by the introduction of the gelatine dry plate about I880, and its astronomical possibilities were soon exemplified by the successful photographs obtained of the comets of I88I and I882. In the latter case Sir David Gill assisted the local photographers by letting them strap their camera to an equatorial, with very successful results ; he was impressed by the number of faint stars that were visible on the plates, and the idea of a southern photographic Durchmusterung quickly matured in his mind. He found a willing collaborator in Kapteyn, who volunteered to conduct the measurements and reductions at Groningen. Funds were collected from various sources; the Government Grant Committee of the Royal Society voted 300 . in each of the years 1885 and I886; this was, however, stopped in 1887 , it is believed from the notion that the Astrographic Catalogue, which was then inaugurated, would obviate the need for the Durchmusterung. If that was the idea, subsequent events have proved it to be incorrect. The Astrographic Catalogue is still far from completion, while the Durchmusterung has been available as a standard work for a quarter of a century. It might have been made more perfect but for shortage of funds: the plates admitted measurement to seconds of arc, but in practice this was limited to tenths of minutes. Moreover, it was only carried to declination $18^{\circ} \mathrm{S}$., instead of to the equator. With a view of shortening the reductions, Kapteyn devised an ingenious measuring instrument, which was practically a small equatorial placed in the position, relatively to the plate, occupied by the centre of the camera lens, the principle being that, since the rays through this point suffered no bending, the star-images, viewed from here, have the same configuration as the stars themselves. Hence right ascension and declination could be read from the circles.

The whole work occupied thirteen years, nearly double the original estimate, but the time was spent ungrudgingly by Kapteyn, and the close examination and discussion of the results brought to light many interesting facts, such as the change of colour-index with galactic latitude, the galactic stars being bluer than the non-galactic ones. It was also found by careful counts that there was no sensible difference in the number of stars recorded at the centres of the plates and near their edges. Several cases of light variation and of rapid proper motion were also found. The question of photographic stellar magnitudes was still in its infancy, but a simple formula was found, mag. $=\mathrm{B} /(\mathrm{C}+$ diam. $), \mathrm{B}$ and $\mathrm{C}$ being constants for the plate; as these are printed, it is possible to recover the diameter of each star.

Kapteyn was elected an associate of the Royal Astronomical Society in 1892 , and received its Gold Medal in 1902 in appreciation of his work on the Durchmusterung. This was, however, only one of the numerous researches that he undertook to investigate the structure of the sidereal universe. He saw the need for increased knowledge of stellar parallaxes. In $r 886$ he investigated the parallaxes of forty-five stars by the method of meridian transits (since found to be less accurate than the photographic method), and endeavoured to secure that the astrographic plates should each have three exposures at dates of maximum parallactic displacement. This was not

NO. 2749 , VOL. I IO] 